\title{
ARQUEOLOGÍA DE LA BOCA DEL RIACHUELO. PUERTO URBANO DE BUENOS AIRES, ARGENTINA
}

WEISSEL, MARCELO N. ${ }^{\text {I }}$

Fecha de Defensa: 18 de Agosto de 2008 - Director: Dr. José Luis Lanata - Co-Director: Dr. Fernando Devoto

Jurados: Dres. Víctor Durán, Dolores Elkin y María Ximena Senatore

Desde la conquista europea de América, los puertos son imprescindibles para la vida en las ciudades litorales. En la cuenca del Río de la Plata, aparecen usos culturales del espacio que producen, importan y descartan tecnologías aplicadas a paisajes ocupacionales portuarios. En este sentido, los puertos son centros económicos y sus poblaciones desarrollan dinámicas culturales propias. Diferentes autores han estudiado procesos portuarios de manera coincidente con el estudio de la explotación humana de ambientes litorales fluviales, marinos, estuáricos y de humedales. Aún así, el estudio del puerto urbano en Sudamérica ha sido poco abordado.

La Boca del Riachuelo puede concebirse como un puerto urbano; una organización social de prácticas de intercambio y modos de transporte en una ciudad. Sin embargo, hoy, puerto y ciudad se encuentran separados. La actividad de La Boca cesa casi por completo hacia finales de siglo XX y sus otrora áreas activas se han convertido en lugares de acceso restringido, tal como sucede en otros emplazamientos portuarios -i.e. astilleros, terminales portuarias. En consiguiente, los lugares que aún contienen información sobre la época de convivencia puerto-ciudad constituyen sitios arqueológicos con información acerca del pasado. A fin de investigar esta temática planteamos dos factores principales de variabilidad artefactual. Uno es el factor portuario, que produjo la valoración de la ribera, y desarrolló infraestructura institucional, aduane- ra, gremial y patronal, propia de los puertos. Otro es el factor urbano, pues organizó el ambiente como lugar de residencia y actividad permanente, generando nuevas necesidades. La suma de factores fue conformando usos espaciales que seleccionaron bienes particulares y los manejaron en diferentes cantidades y diversidades. Este desarrollo aseguró a través del tiempo, la conformación, consolidación y mantenimiento de un sistema de ocupación tecnológico del espacio, sustentado en las conductas humanas que produjeron matrices sedimentarias multifuncionales. En esta investigación discutimos las propiedades que estructuran su registro arqueológico y conforman la variabilidad del asentamiento.

\section{MARCO TEÓRICO METODOLÓGICO: ARQUEOLOGÍA URBANA DISTRIBUCIONAL}

El estudio de las propiedades del registro arqueológico, a través de la distribución artefactual contribuye al conocimiento de las tecnologías del puerto urbano, permitiendo modelar las estrategias que organizaron el intercambio, las formas de asentamiento, sociabilidad y edificación, y las actividades socio-económicas desplegadas en la región de manera cambiante a través del tiempo. Es importante destacar que desde la arqueología existen herramientas que permiten plantear y responder preguntas, considerando los problemas de formación de sitio y la historia am-

\footnotetext{
${ }^{\text {I }}$ Fundación de Historia Natural Félix de Azara (CEBbAD), Universidad Maimónides • Convenio Comisión para la Preser vación del Patrimonio Histórico Cultural de la Ciudad de Buenos Aires, Ministerio de Cultura GCaba • Valentín Virasoro 732, C1405BDB Ciudad AutónOma de Buenos Aires • E-Mall: weisselmarcelo@hotmail.com
} 
biental regional con una perspectiva distribucional. Considerando, en primera instancia, las condiciones ambientales naturales, observamos que las mismas sientan la configuración regional de los depósitos. El barrio de La Boca ${ }^{1}$ aprovechó las condiciones estratégicas litorales para el enlace del transporte naval con el terrestre; sin embargo, enfrentó problemas desde el punto de vista del asentamiento humano. Es una zona de dinámica hidrológica particular que incide en la resistencia portante de la geomorfología. Para hacer frente al comportamiento de la naturaleza, se hizo necesaria infraestructura tecnológica adecuada. Los artefactos adquirieron protagonismo en la construcción de un nuevo espacio físico.

Considerando en segunda instancia, el desarrollo de paisajes ocupacionales como la recepción, reparación, construcción y despacho de embarcaciones en el abrigo natural del Riachuelo. Esto promovió el incremento del volumen mercantil y de tránsito de personas, junto al desarrollo de las fuerzas productivas y el equipamiento creciente. De esta manera, observamos la construcción de infraestructura laboral y doméstica que resulta fundamental en la conformación arqueológica del puerto - ciudad, pues representan la acumulación de artefactos en el espacio. En consiguiente, la ocupación tecnológica del espacio constituyó un nuevo hábitat dominado por el accionar humano. Hoy en día el grado de contaminación que afecta al Riachuelo lo identifica como uno de los ambientes más antropizados de la Argentina. En este sentido, entendemos que los procesos de portuarización y urbanización son factores decisivos en la constitución de la tecnósfera ${ }^{2}$. De esta manera, se observa la necesidad de concebir escalas portuario-urbanas de análisis del registro arqueológico.

Desde el planteo teórico metodológico, asumimos que quienes habitaron dentro de una economía de mercado, jerarquizaron a los artefactos como bienes de valor. Esto produjo una organización tecnológica de grupos -e individuos- que, dentro de la lógica capitalis- ta, gestionaron bienes muebles e inmuebles. Esta idea nos permite formular preguntas, considerando el rol de los conjuntos artefactuales. En los estudios distribucionales, los artefactos se emplean como indicadores de cualidades estructurales del registro arqueológico -i.e. forma, composición y variabilidad a los fines de inferir actividades humanas.

Este diseño de investigación, permitió integrar la información regional recolectada durante diez años de trabajos de campo. Se trabajó con tres mil artefactos recuperados de 32 sitios arqueológicos muestreados de una superficie regional de $13 \mathrm{~km} 2$ perteneciente a los barrios de La Boca, Barracas y Puerto Madero. La región fue dividida en cuatro áreas: el área 1, disponible para la ocupación humana desde la urbanización y portuarización de la ciudad a fines del siglo XIX. Se ubica sobre la costa del estuario del Río de la Plata, en el sector de la desembocadura del Riachuelo e incluye también un sitio en Puerto Madero; el área 2 comprende las cotas de 0 a 5 metros, donde pueden identificarse dos sub áreas. Posee características fluvio-estuáricas de la cuenca baja del Riachuelo, con un sector externo sobre la línea de ribera, y otro sector interno dentro de la planicie de inundación. El Área 2 externa, es la más próxima a las márgenes del Riachuelo. El Área 2 interna, se encuentra alejada de la costa del Riachuelo. Tiene una urbanización tardía, y por lo tanto el potencial de hallazgos se ajusta a esa cronología. El Área 3, se extiende en las zonas más elevadas de la planicie por encima de la altura de las inundaciones históricas.

Los hallazgos fueron clasificados en gabinete, en base a su asignación funcional, conformando una base de datos de 6 categorías principales (Comunicación, Medicina, Higiene y Estética, Lúdica, Alimentación, Laboral). A partir de la evaluación de los procesos de formación, utilizando índices de integridad (i.e. visibilidad, foco, residualidad, redepositación) y de esta tipología se cuantificaron los usos artefactuales para evaluar una serie de hipótesis. 


\section{OBJETIVOS}

El objetivo general es el estudio, a través del registro arqueológico, de la diversidad y distribución artefactual en un medio portuario y urbano como lo es el barrio de La Boca, Ciudad Autónoma de Buenos Aires. Los objetivos buscaron:

- Conocer las propiedades del registro arqueológico que permiten diferenciar paisajes arqueológicos en tiempo y espacio.

- Identificar la densidad, la distribución y la diversidad artefactual.

- Analizar la variabilidad y la continuidad del asentamiento.

- Definir las estrategias implementadas en relación a la organización de la tecnología y el espacio portuario urbano.

\section{RESULTADOS ALCANZADOS}

El enfoque teórico distribucional sirvió para estudiar los artefactos como unidades de análisis del paisaje. Esto resultó muy efectivo para medir distribuciones, diversidad y densidad de los conjuntos artefactuales. Con el análisis de la diversidad se logró una aproximación a la variabilidad regional. Los índices estadísticos de riqueza, heterogeneidad $\mathrm{H}$ y homogeneidad J posibilitaron analizar los artefactos en conjuntos de categorías. Esto permitió producir inferencias arqueológicas sobre la constitución y el desarrollo del paisaje entre los siglos XVIII y XX. El enfoque teórico también fue muy útil para identificar las actividades y las estrategias que originaron la organización tecnológica del espacio. Los resultados indican que la densidad, a escala regional, se incrementa paulatinamente. La mayor densidad se observa en el Área 2 interna -ámbitos domésticos-, con un predominio regional de la categoría Alimentación. La densidad por categoría indica que Alimentación predomina en el inicio del lapso estudiado, para ser superada por lo Laboral al promediar la extensión cronológica. Alimentación vuelve a ser la categoría más densa hacia el final del lapso temporal, seguida de Higiene y Estética. Los resultados regionales destacan la intensidad de la distribución de frecuencias artefactuales en el Área 2 interna y en el Área 3. Esto se debe a que allí se ubican los sitios domésticos. También indican que, a escala regional, la categoría Laboral aumenta y luego desciende mientras que Alimentación desciende y luego aumenta a través del tiempo. El resto de las categorías aumenta su distribución hacia el final del marco cronológico. La baja densidad artefactual del Área 1 puede explicarse por el desarrollo de una estrategia moderna de ocupación del espacio -la más tardía de la región- tomando como base las áreas 2 externa y 2 interna. En este sentido, el Área 1 (sección Boca y Puerto Madero) es de ocupación tardía. Podemos decir que durante la consolidación del asentamiento urbano, se produce un área arqueológica dedicada al trabajo sin vivienda. Incluida en un proyecto de construcción integral de un puerto moderno para la ciudad, que se dedicará al comercio a gran escala, la producción de energía eléctrica y la urbanización controlada con sectores de recreación -i.e. parquización en plaza Solís, y primeras canchas de fútbol de River Plate y Boca Juniors. Las muestras son pocas pero en ellas es posible observar las huellas de los procesos actuantes y la relevancia de las actividades portuarias y productivas para la economía del asentamiento.

El Área 2 externa presenta diferentes frecuencias en las categorías estudiadas -i.e. no hay registro de material lúdico (niñez) hasta el último cuarto del lapso estudiado. La evidencia de artefactos relacionados con la Comunicación es baja. La Medicina tiene muy alta representación hacia el último cuarto de siglo XX, coincidente con el momento de mayor cantidad de habitantes; mientras que lo Laboral es muy importante hacia la mitad del periodo estudiado. Esto no quiere decir que hacia el inicio no haya habido trabajo ni enfermedades, sino que el registro es de difícil asignación funcional. 
El Área 2 interna muestra que su ocupación se relaciona al uso intensivo de la ribera a partir de la década de 1870, momento en que se incrementa la presión poblacional inmigratoria. Aquí es donde vivienda y trabajo se asocian fuertemente. Esto es visible en los sitios muestreados, la gente -los trabajadores traen consigo sus instrumentos y su comida a los lugares de trabajo -Alimentación y Laboral- lo que produce un salto en la variabilidad artefactual hacia el final del marco cronológico. Para ese momento, los sitios indican el desarrollo de actividades domésticas, mayor inversión de energía y capital que previamente. Los habitantes se equipan con más productosbienes en sus actividades cotidianas, que van desde cubrir los servicios sanitarios -salud, desagües, iluminación- y el mantenimiento residencial, hasta el desarrollo de identidades alimenticias, lúdicas y recreacionales -juegos infantiles, deportes y pertenencia a clubes, carnavales- propias. La evidencia de artefactos relacionados a la Medicina tiene muy alta representación hacia fines de siglo XX, lo que puede reflejar el desarrollo de enfermedades en la población de conventillos.

El único sitio del Área 3 indica la ocupación temprana de carácter doméstico y una ocupación posterior de carácter laboral industrial.

El análisis de la diversidad instrumental produjo resultados sobre la forma, la composición y la variabilidad de los conjuntos artefactuales. Las clases recuperadas llegan a 6 en el total de las 32 muestras arqueológicas. El promedio de clases en cada sitio es de 3,281 con un desvío estándar de 1,800. La categoría presente en todos los sitios es Alimentación. La proporción entre la categoría mayor y menor es de 15,35. La media de valores J es de 0,3649 con valores de desvío estándar de 0,2585 . La media de valores $H$ es de 0,6663 con un desvío estándar de 0,4886. El valor de correlación entre $\mathrm{H}$ y J es de r: 0,9837. La variabilidad regional en la frecuencia de hallazgos es grande, fluctuando entre 1 y 719 elementos por sitio. Por su parte, los índices $\mathrm{H}$ sobre heterogeneidad presentan una varia- bilidad importante en el Área 1 y el Área 2 interna. Esto concuerda con una diversidad regional que concentra sus valores más altos en los sitios domésticos o laborales-domésticos tardíos. La distribución de la mayor diversidad -i.e. índice $\mathrm{H}$ de heterogeneidad de los conjuntos artefactuales, se registra en sitios de vivienda -conventillos- seguidos de los sitios donde se proveyó de servicios portuarios -fonda, almacén, astillero. Se destaca que a mayor domesticidad, mayor diversidad artefactual. En este sentido, la distribución responde a la incidencia de la actividad portuaria -localización de espacios laborales- y urbanos -vivienda y comercio minorista- desarrollados en el tiempo y el espacio.

La discusión de los resultados destaca la presencia de patrones particulares de registro, que indican el desarrollo de estrategias de organización tecnológica diferencial del espacio. Se destaca su ocupación desde el inicio del siglo XVIII hasta mediados de siglo XIX, con actividades domésticas en el alto de la planicie de inundación fluvio-estuárica y actividades portuarias en la franja costera del Riachuelo. Hacia finales de siglo XIX se registra la ocupación del interior de la planicie de inundación y la costa del estuario. Durante el siglo XX, la actividad desciende y el registro se concentra en las zonas de mayor depositación relacionadas a la vivienda, donde se emplazan conventillos e inquilinatos. Se distingue la importancia del instrumental del puerto urbano identificada en la densidad, diversidad y distribución de las muestras. Las actividades y oficios inferidos a partir de los artefactos destacan que la Alimentación es el productor principal de desechos, tanto en contextos arqueológicos laborales como domésticos, seguidas respectivamente por las categorías Laboral, Higiene y Estética, Lúdica, Medicina y Comunicación. A través de los años observamos la influencia y la variabilidad de actividades conexas a la alimentación que dan forma a muchos depósitos del paisaje en el cual vivimos. Es el caso del espacio laboral, fundamentalmente la ribera, que implica la organización de la vida cotidiana y las necesi- 
dades básicas de sus habitantes. La construcción y uso masivo de los conventillos desde el último cuarto de siglo XIX, marca el inicio de una mayor representación artefactual en el registro arqueológico regional de lo doméstico por sobre lo laboral. Por consiguiente, la vivienda en el ámbito de los puertos en general y en el de La Boca en particular plantea nuevos interrogantes. Diferentes clases de estructuras -i.e. superficiales y subsuperficiales, flotantes, palafíticas, de mampostería, de metal, etc.- pueden indagarse como condicionantes tecnológicos - culturales para la producción de relaciones sociales.

En cuanto a la continuidad y a la variabilidad, la Alimentación es la categoría de artefactos aprovechada con mayor continuidad. Lo mismo podemos decir del asentamiento; la utilización artefactual constante en la producción de matrices sedimentarias multi-funcionales estableció la forma de construir un nuevo hábitat. La riqueza y la heterogeneidad de los conjuntos artefactuales se incrementan en función del paso del tiempo y de la mayor presencia de ámbitos domésticos que urbanizan el paisaje. Los resultados alcanzados nos permiten concluir que la homogeneidad del instrumental estuvo condicionada por la variabilidad del proceso de conformación del espacio. Mientras que los conjuntos artefactuales tempranos son homogéneamente similares -con el predominio de actividades alimenticias seguidas de laborales; desde fines de siglo XIX se observan cambios en las proporciones de las categorías de artefactos, haciendo su aparición categorías que en los periodos iniciales no figuran en el registro. Este es el caso de la Medicina, la Higiene y Estética, la Comunicación y la Lúdica. Desde la perspectiva distribucional arqueológica, esta variabilidad se debe a diferentes estrategias de organización espacial basadas en la naturaleza, composición y frecuencia de las prácticas socio-profesionales, fundadas en el incremento poblacional.

En conclusión, dentro del modelo de ocupación tecnológica del espacio quedan com- prendidas las acciones de individuos y grupos de individuos que influidos por factores portuarios y urbanos desarrollan operaciones de construcción, uso y transformación de $\mathrm{La}$ Boca del Riachuelo. En este sentido, las actividades laborales y domésticas conforman estrategias de organización de la tecnósfera del Riachuelo, como hábitat portuario urbano integrado al mercado laboral y de productos y a la historia económica y social argentina.

\section{NOTAS}

1. $34^{\circ} 38^{\prime} 12,26^{\prime \prime} \mathrm{S}$ y $58^{\circ} 21^{\prime} 33,74^{\prime \prime} \mathrm{W}$, marcado en el sitio dónde funcionó el Juzgado de Paz, desde el 23 de agosto de 1870, institución de la autonomía jurisdiccional, Iglesia San Juan Evangelista, calle Olavarría no 486.

2. Nos referimos a un ambiente compuesto de fragmentos de ecosistemas terrestres transformados, los cuales no pueden ser entendidos a la luz de procesos ecosistémicos sino en relación a dispositivos y procesos tecnológicos que la cultura humana ha creado para producir materiales y energía (Geo Argentina. SAyDS NA 2004: 45).

Nota: Por razones de espacio no se consigna la bibliografía pertinente. 
